\title{
PENGARUH KUALITAS WEBSITE DAN KUALITAS SERVICE TERHADAP LOYALITAS MELALUI KEPUASAN PENGGUNA SHOPEE
}

\author{
Wahyu Widiya Ningsih ${ }^{1)}$, Ida Bagus Nyoman Udayana ${ }^{2)}$ Lusia Tria Hatmanti Hutami ${ }^{3)}$ \\ ${ }^{1}$ Fakultas Ekonomi Prodi Manajemen, Universitas Sarjanawiyata Tamansiswa Yogyakarta \\ E-mail: widiyawahyu85@gmail.com \\ ${ }^{2}$ Fakultas Ekonomi, Prodi Manajemen, Universitas Sarjanawiyata Tamansiswa Yogyakarta \\ E-mail: Ibn.udayana@yahoo.co.id \\ ${ }^{3}$ Fakultas Ekonomi, Prodi Manajemen, Universitas Sarjanawiyata Tamansiswa Yogyakarta \\ E-mail: trialusia@gmail.com
}

\begin{abstract}
This research was conducted with the aim of knowing and analyzing what could affect the loyalty of Shopee e-commerce users. With several variables contained in this study, namely, website quality, service quality, user satisfaction and loyalty. In this study, there is a population namely Shopee e-commerce users and customers. And sampled a number of 100 respondents who use and subscribe to Shopee ecommerce. In taking a sample in this study using a probability model sampling technique or random sampling. This technique is a sample return technique where each member of the population has an equal chance of being selected as a semple member. After processing the data with SPSS 20, this research shows that website quality and service quality have a positive effect on user satisfaction, and user satisfaction has a positive effect on loyalty. The results of these calculations show that the sig value is positive, therefore all variables are accepted because they have a positive influence.
\end{abstract}

Keywords : website quality, service quality, user satisfaction, loyalty

\section{PENDAHULUAN}

Perkembangan internet saat ini memiliki pengaruh yang sangat besar dalam setiap aspek kehidupan termasuk bisnis. Saat ini kita disa belanja dari mana pun kita berada, hanya dengan ecommerce kita dapat melakukan transaksi jual beli tanta harus pergi ke toko, akan hanya dengan Smartphone. E-commerce adalah aktifitas penggunaan teknologi informasi dan komunikasi pengolahan digital dalam melakukan transaksi bisnis untuk menciptakan, mengubah, dan mendefinisikan kembali hubungan antara penjual dan pembeli. Belanja online menjadi alternatif bagi setiap orang hal tersebut dikarenakan pengguna online shopping dapat menerima barang atau jasa tanpa harus pergi ke toko hal tersebut sangat digamari masyarakat terutama anak muda yang mempunyai gaya hidup yang praktis hehingga paling cocok dengan belanja online. Karena dengan kepraktisan dari e-commerce tersebut menyebabkan pertumbuhan dari e-commerce sangat pesat di Indonesia. Hal ini dilangsir dari Lembaga riset asal inggris, merchat, meliris daftar sepuluh negara dengan pertumbuhan e-commerce tercepat di dunia.(Katadata.co.id, 2019) 


\section{Gambar 1.1 \\ Grafik Pertumbuhan E-Commerce}

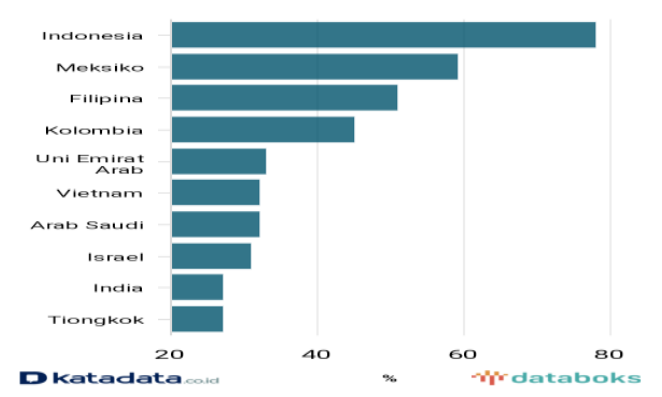

sumber: databoks 25-04-2019 jam 16:30

Dalam gambar 1.1 diatas menunjukkan bahwa Indonesia menjadi negara tercepat dalam pertumbuhan e-commerce. Shopee merupakan e-commerce yang terkenal di Indonesia, yang memiliki sasaran pengguna yaitu pada kalangan muda yang masih melakukan kegiatan dengan bantuan gadget untuk melakukan kegiatan belanja. Untuk itu shopee hadir dalam bentuh mobaile guna menjunjung kepraktisan dalam berbelanja. Shopee adalah e-commerce pertama diasia tenggara, Shopee didirikan oleh Forrest Li pada tahun 2009 dan dipimpin oleh Chris Feng. Shopee masuk dan beroperasi di Indonesia pada 2015.

Rumusan masalah pada penelitian ini adalah bagaimanakah pengaruh kualitas website terhadap kepuasan pengguna Shopee? Bagaimana pengaruh kualitas service terhadap kepuasan pengguna Shopee? Dan bagaimana pengaruh kualitas website dan kualitas service terhadap loyalitas melaluhi kepuasan pengguna Shopee? Sedangankan untuk tujuan dari penelitian ini dadalah untuk mengetahui seberapa besar pengaruh dari kualitas website terhadap kepuasan pengguna Shopee, seberapa besar pengaruh dari kualitas service terhadap kepuasan pengguna, dan seberapa besar pengaruh kualitas website dan kualitas service terhadap loyalitas melalui kepuasan pengguna Shopee.

Kualitas website adalah hal yang paling berpengaruh dalam penjualan. Website yang berkualitas yaitu dengan memberikan suatu informasi yang lengkap entah informasi kekurangan ataupun kelebihan suatu barang kepada pembeli, sehingga pembeli tidak merasa tertipu karena sudah membeli barang yang tidak sesuai dengan yang diharapkan.

Kualitas service juga sangatlah penting dalam penjualan, dengan pelayanan yang baik inilah menjadikan pembeli akan merasa puas dengan transaksi yang sedang mereka jalani sehingga pmbeli yang puas akan melakukan transaksi Kembali pada perusahaan yang sama.

Kepuasan pengguna yaitu sebuah sikap yang dapat dijadikan penilaian pembeli dengan cara apakah produk yang dibeli sesuai dengan harapan pembeli ataukah sangat jauh dari yang diharapkan pembeli.

Loyalitas dapat didasari dengan website dan juga service yang berkualitas sehingga menjadikan pembeli tersebut puas dan pembeli tersebut akan melakukan pembelian ulang dan juga akan setia kepada perusahaan, lalu merekomendasikan produk kepada teman-temannya. 


\section{Loyalitas}

Loyalitas merupakan kesetiaan pelanggan dalam pembelian barang atau jasa pada suatu perusahaan, menurut(Udayana \& Mujino, 2018) loyalitas perlu untuk diperhatikan dalam jangka waktu yang Panjang, hal ini dikarenakan mempertahankan pelanggan lebih sulit daripada mendapatkan pelanggan baru. Oleh sebab itu perusahaan harus sungguh-sungguh dalam mempertahankan kebutuhan dari pelanggan yang sudah ada. Menurut Griffin (2005) yang dikutip (Puspitasari et al., 2010) mengungkapkan bahwa loyalitas memiliki tahapan-tahapan, yaitu:

a. tersangka (suspect) atau orang yang diperkirakan akan membeli produk.

b. Prospek yaitu orang yang membutuhkan produk atau jasa dan memiliki kemungkinan membeli produk atau jasa tersebut.

c. Prospek yang diskualifikasi yaitu prospek yang cukup dipelajari untuk pembelian tetapi tidak memiliki kemungkinan untuk pembelian karena tidak membutuhkan barang.

d. Pelanggan pertama kali yaitu orang membeli satu kali, orang tersebut bisa menjadi pelanggan kita sekaligus pelanggan pesaing

e. Klien membeli apapun yang dijual dan dapat digunakan. Memiliki hubungan yang kuat dan berlanjut, hal tersebut menjadikan kebal dari tarikan pesaing.

f. Penganjur (advocate) sama halnya dengan klien, pendukung membeli apapun yang dijial dan dapat digunakan serta membelinya secara teratuh, setelah itu pembeli akan mempromosikan kebada orang lain.

\section{Kepuasan Pengguna}

Kepuasan pengguna adalah sebuah rasa kepuasan atau ketidakpuasan konsumen saat menilai produk yang dibeli apakah sesuai dengan yang mereka harapkan ataukah tidak sesuai dengan harapan konsumen. Menurut (Udayana \& Mujino, 2018) perusahaan memiliki tugas yaitu meyakinkan pelanggan bahwa produk yang dibeli adalah terbaik. Untuk itu perusahaan harus memiliki strategi yaitu dengan memberikan informasi yang selengkapnya mungkin kepada pelanggan mengenai produk yang mereka beli baik kekurangan ataupun kelebihan dari barang tersebut.

Menurut Iwan (2008) dari (Insana \& Johan, 2020), terdapat lima faktor yang perlu diperhatikan oleh penjual dalam menentukan kepuasan konsumen, anatara lain:

1) Kualitas produk, pelanggan akan merasa puas jika barang yang mereka gunakan berkualitas.

2) Kualitas pelayanan dan jasa, pelanggan akan merasa puas jika mereka mendapatkan pelayanan yang baik dan sesuai dengan yang diharapkan.

3) Emosi, pelanggan akan merasa bangga dan mendapat keyakinan bahwa orang lain akan kagum terhadap dia, apabila memakai produk merek tertentu yang cenderung memiliki kepuasan yang tinggi.

4) Harga, pembeli akan merasa puas jika mereka mendapatkan produk yang berkuaalitas tinggi akan tetapi dangan harga yang lebih murah.

5) Biaya, yaitu pelanggan tidak perlu mengeluarkan biaya tambahan atau tidak perlu membuang waktu untuk mendapatkan suatu barang atau jasa tersebut. 


\section{Kualitas Website}

Website adalah hal yang paling penting Ketika dihadapkan dengan bisnis online. Hal tersebut dikarenakan bahwa website yang berkualitas maka akan menarik pembeli bahkan akan menjadikan pembeli tersebut puas, dapat dicontohkan pembeli akan merasa puas jika dalam website sudah di berikan informasi-informasi yang terdapat dalam produk, jadi pelanggan tidak akan salah beli produk. Menurut Olsina dalam (Indriyani \& Helling, 2018) kualitas website mengevaluasi, kualitas isi yang terdapat pada website pada website dalam beberapa hal seperti navigasi, keindahan, fungsi, dan hal lainnya yang mempengaruhi. Menurut Swastika 2016) yang dikutip(Hapsari \& Priyadi, 2017) kualitas website memiliki dimensssi yaitu sebagai berikut:
a. Kualitas pengguna (usability quality)
b. Kualitas informasi (information quality)
c. Kualitas layanan interaksi (interaction quality)

\section{Kualitas Service}

Kualitas service (kualitas pelayanan) adalah alat ukur seberapa baiknya pelayanan yang iterapkan perusahaan. Menurut Kotler dalam (Lubis \& Andayani, 2018) kualitas service adalah sebuah kinerja yang dapat ditawarkan oleh seseorang kepada orang lain. Menurut Yulianti \& Umbara, (2020) kualitas layanan yang baik bukanlah berdasarkan sudut pandang atau persepsi pihak penyedia layanan, melainkan dari sudut pandang dan presepsi pengguna. Sehingga pelayanan yang berkualitas dinilai dari apakah pengguna tersebut merasa puas dengan pelayanan yang diberikan perusahaan.

\section{METODE PENELITIAN}

Sifat dari penelitian ini adalah kuantitatif, dengan menggunakan data primer yang didapatkan dari jawaban kuesioner dan diolah menggunakan SPSS. Dalam pengambilan sample pada penelitian ini menggunakan Teknik probalitas samping. (Wiyono, 2011), pengambilan sample probabilitas yaitu metode pemilihan sample dimana setiap anggota memiliki peluang yang sama. Dalam penelitian ini peneliti menggunakan responden 100 pengguna Shopee. Penelitian ini menggunakan metode regresi berganda. Dalam penelitian ini penulis membagi dua model untuk mengolah data karena terdapat empat variabel yaitu variabel kualitas website sebagai X1, kualitas service sebagai X2, kepuasan pengguna sebagai Y1 dan loyalitas sebagai Y2. Model dari penelitian ini mengembangkan penelitian yang sudah ada, yaitu dari (Susanto et al., 2013) 


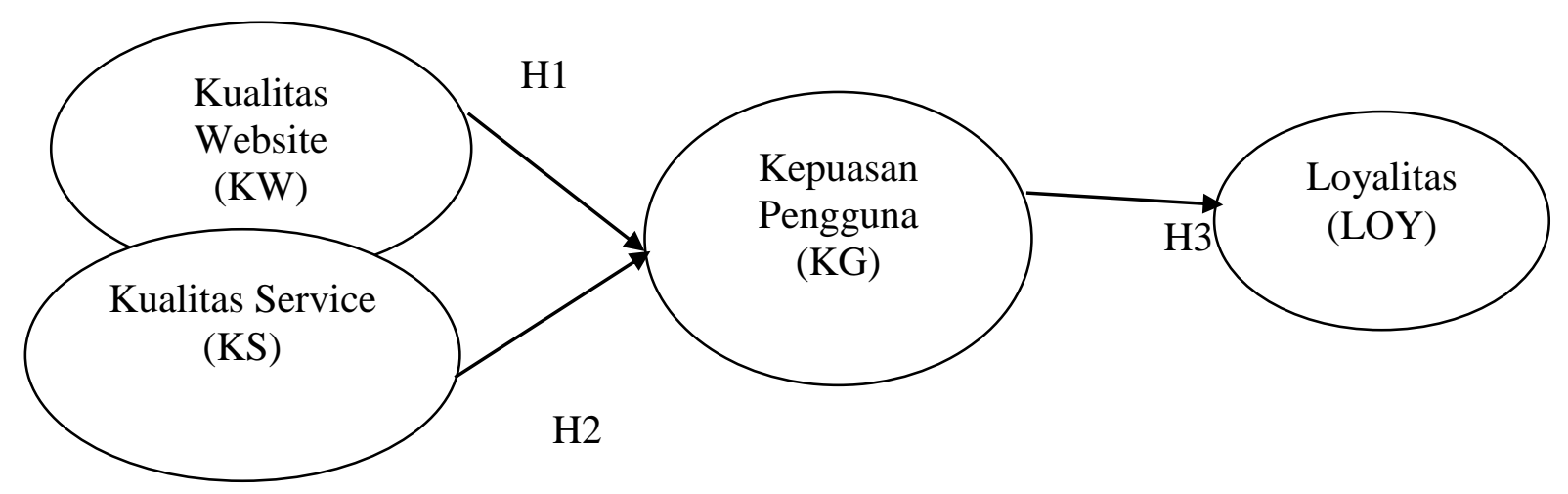

\section{HASIL DAN PEMBAHASAN}

Uji Asumsi klasik

a. Normalitas

Uji ini bertujuan untuk menguji anatara variabel dependen dan variabel intependen dalam model regresi ini memiliki distribusi normal atau tidak. Regresi yang baik adalah yang memiliki distribusi yang normal atau mendekati normal.

Gambar 3.1

Grafik histogram variabel dependent kepuasan pengguna

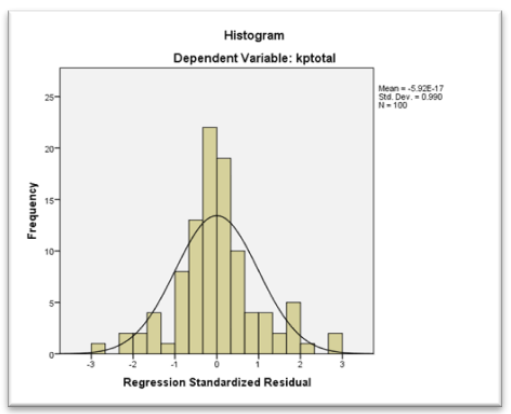

Gambar 3.2

Gfafik histrogram, variabel dependent loyalitas

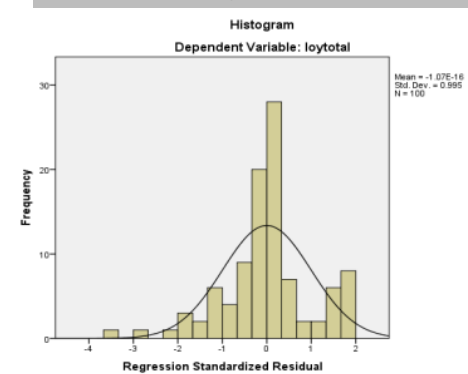

Dari kedua grafik diatan menunjukkan kedua grafik tersebut berbentuk simetris dan terlihat miring terjajar ke bagian kiri dan kanan grafik sehingga dapat disimpulkan bahwa hasil seluruh seluruh pengolah data diatas dinyatakan normal. 
b. Uji multikolinieritas

Uji mulitkolinieritas bertujuan untuk mengetahui ada tidaknya penyimpanan asumsi klasik mulitkolinieritas, yaitu dengan adanya hubungan linier variabel independen dalam model regresi. (Wiyono, 2011) menjelaskan bahwa ada persyaratan yang harus dipenuhi dalam model regresi yaitu sebagai berikut:

- Dengan melihat nilai inflation factor (VIF)

- Dengan membandingkan nilai koefisien determinasi individual $\left(\mathrm{r}^{2}\right)$

- Dengan melihat nilai eigenvalue dan condition index

Tabel 3.1

Uji Mulitkolinieritas

\begin{tabular}{l|lll}
\hline Variabel & Tolerance & VIF & Kesimpulan \\
\hline Kualitas website & .421 & 2.377 & Tidak terjadi multikolinieritas \\
Kualitas service & 421 & 2.377 & Tidak terjadi multikolinieritas \\
Kepuasan pengguna & .421 & 2.377 & Tidak terjadi multikolinieritas \\
Loyalitas & 1.000 & 1.000 & Tidak terjadi multikolinieritas
\end{tabular}

Dari tabel tersebut menenunjukan bahwa tidak terjadi mulitikolinieritas pada model penelitian ini, karena seluruh nilai tolerance lebih besar dari 0,10. Dan nilai VIF lebih kecil dari 10,00 yang berarti tidak terjadi multikolinieritas pada hasil uji diatas.

c. Uji Heterokedasitas

Uji Heterokedastisitas digunakan untuk mengetauhi ada atau tidaknya penyimpangan asumsi klasik heterokedastisitas, yaitu adanya ketidaksamaan varian dari residual untuk semua pengamatan pada semua model regresi. Ada beberapa metode pengujian yang dapat digunakan yaitu: uji park, uji Glesjer, melihat pola grafik regresi, dan uji koefisian korelasi spearman. Adapun krietia pengujian yaitu sebagai berikut:

$\mathrm{H}_{0}$ : tidak ada gejala heterokedastisitas

$\mathrm{H}_{\mathrm{a}}$ : ada gejala heterokedistisitas

$\mathrm{H}_{0}$ diterima jika $-\mathrm{t}$ tabel $\leq \mathrm{t}$ hitung $\leq \mathrm{t}$ tabel, yang berarti tidak terdapat heterokedastistas

$\mathrm{H}_{\mathrm{a}}$ ditolak jika $\mathrm{t}$ hitung $>\mathrm{t}$ tabel 


\section{Gambar 3.1}

\section{Uji Hiterokedasitisitas, Variabel Dependent Kepuasan Pengguna}

Scatterplot

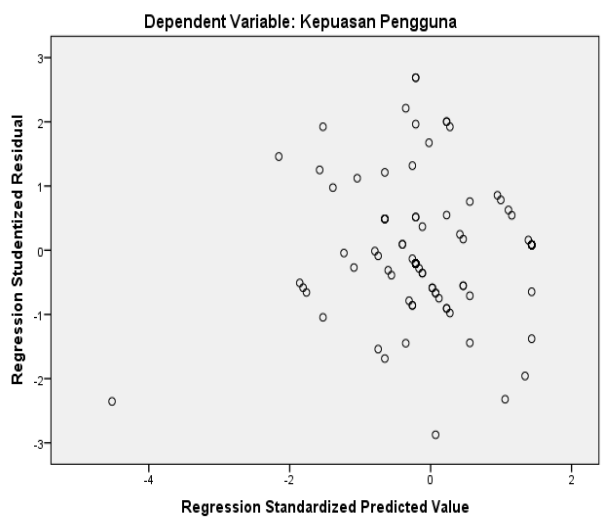

Gambar 3.4

Uji Heterokerdatisitas, Variabel Dependen Loyalitas

Scatterplot

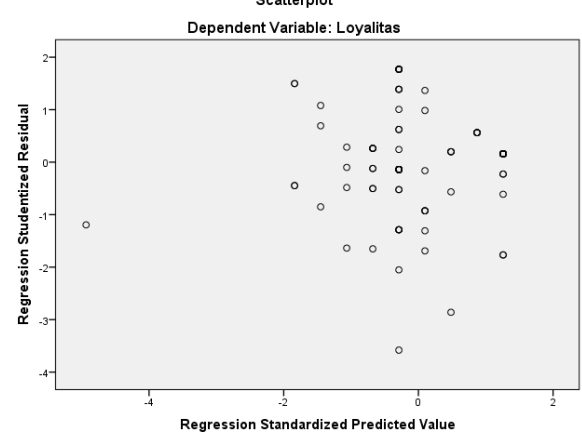

Kedua gambar tersebut menunjukkan berkontribusi normal dan tidak ditemukan adanya heterokedasitas, karena titik-titik yang tersebar pada kedua gambar diagram pancar diatas, tersebar secara merata dibagian kanan dan kiri 0 horizontal dan menyebar diatas dan bawah angka 0 vertikal

\section{Analisis Data}

a. Analisis regresi linier berganda

Tabel 3.2

Analisis Linier Berganda

Variabel Dependen Kepuasan Pengguna

\begin{tabular}{|c|c|c|c|c|c|c|}
\hline \multicolumn{7}{|c|}{ Coefficients $^{\mathrm{a}}$} \\
\hline \multirow{3}{*}{\multicolumn{2}{|c|}{ Model }} & Unsta & & Standardized & \multirow{3}{*}{$\mathrm{T}$} & \multirow{3}{*}{ Sig } \\
\hline & & Coeffi & & Coefficients & & \\
\hline & & B & $\begin{array}{l}\text { Std. } \\
\text { Error }\end{array}$ & Beta & & \\
\hline 1 & (Constant) & 1.891 & 1.036 & & 1.824 & .071 \\
\hline
\end{tabular}




\begin{tabular}{cccccc}
\hline $\begin{array}{l}\text { kualitas } \\
\text { website } \\
\text { kualitas }\end{array}$ & .103 & .053 & .163 & 1.960 & .053 \\
$\begin{array}{c}\text { service } \\
\text { a. Dependent Variable: kepuasan pengguna }\end{array}$ & .959 & .112 & .715 & 8.581 & .000 \\
\hline
\end{tabular}

Dari hasil tersebut menunjukkan bahwa, variabel independent diatas yaitu kualitas website nilai signifikasinya berjumlah 0,053 Yang berarti lebih besar dari nilai $\alpha=0,05$, sedangkan nilai signifikasi variabel independent kualitas service yaitu 0,00 yang berarti lebih kecil dari nilai $\alpha=0,05$. Yang berarti variabel kualitas Website dan kualitas service berpengaruh positif terhadap kepuasan pengguna.

Table 3.3

Analisis Regresi Linier Berganda Variabel Dependen Loyalitas

\begin{tabular}{|c|c|c|c|c|c|c|}
\hline \multicolumn{7}{|c|}{ Coefficients $^{\mathrm{a}}$} \\
\hline \multirow{3}{*}{\multicolumn{2}{|c|}{ Model }} & \multirow{2}{*}{\multicolumn{2}{|c|}{$\begin{array}{l}\text { Unstandardized } \\
\text { Coefficients }\end{array}$}} & Standardize & $\mathrm{T}$ & Sig. \\
\hline & & & & & & \\
\hline & & & & & & \\
\hline \multirow{2}{*}{1} & (Constant) & 3.491 & 1.734 & & 2.013 & .047 \\
\hline & kepuasan & 1.055 & .102 & .721 & 10.307 & .000 \\
\hline
\end{tabular}

a. Dependent Variable: loyalitas

Dari hasil pengolahan data analisis regresi berganda diatas menunjukkan bahwa nilai signifikasi dari variabel independent kepuasan pengguna 0,000 hal tersebut lebih kecil dari nilai $\alpha=0,05$. Yang berarti uji model ini menunjukkan kepuasan pengguna berpengaruh positif terhadap loyalitas

b. Koefisien determinasi (r2)

Table 3.5

Koefisien Determinasi (R) Vaeribel Dependen Kepuasan Pengguna

\begin{tabular}{|c|c|c|c|c|}
\hline \multicolumn{5}{|c|}{ Model Summary } \\
\hline $\begin{array}{l}\text { Mo } \\
\text { del }\end{array}$ & $\mathrm{R}$ & $\begin{array}{l}\mathrm{R} \\
\text { Square }\end{array}$ & $\begin{array}{l}\text { Adjusted R } \\
\text { Square }\end{array}$ & $\begin{array}{l}\text { Std. Error } \\
\text { of the } \\
\text { Estimate }\end{array}$ \\
\hline $\begin{array}{l}1 \\
\text { a. } \\
\text { web }\end{array}$ & $\begin{array}{l}.846^{\mathrm{a}} \\
\text { dictors: }\end{array}$ & $\begin{array}{c}.716 \\
\text { (Constant) }\end{array}$ & $\begin{array}{l}.711 \\
\text { kualitas se }\end{array}$ & $\begin{array}{l}1.390 \\
\text { ice, kualitas }\end{array}$ \\
\hline
\end{tabular}


Dari hasil uji $\mathrm{R}$ diatas, yang disajikan pada table 4.17 diatas yang menunjukkan $\mathrm{R}$ Square 0,716, yang artinya pengujian tersebut terdapat $71,6 \%$ pengaruh variabel kualitas website dan kualitas service terhadap kepuasan pengguna. Dan 28,4\% lainnya dipengaruhi oleh variabel lainnya

Table 3.6

Koefisien Determinasi (R)

Variabel Dependen Loyalitas

Model Summary

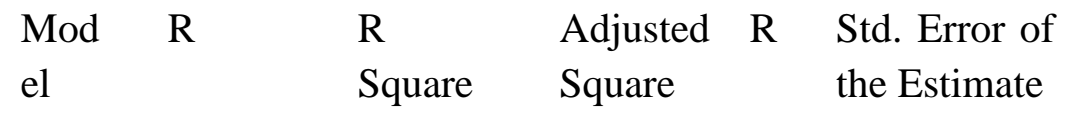

$\begin{array}{lllll}1 & .721^{\mathrm{a}} & .520 & .515 & 2.631\end{array}$

a. Predictors: (Constant), kepuasan pengguna

Sumber data primer: diolah pada tahun 2021

Dari hasil uji R diatas, yang disajikan pada table 4.18 diatas yang menunjukkan $\mathrm{R}$ Square 0,520, yang artinya pengujian tersebut terdapat $52 \%$ pengaruh variabelkepuasan pengguna terhadap loyalitas. Dan $48 \%$ lainnya dipengaruhi oleh variabel lainnya.

d. Uji simultas $(\mathrm{F})$

Table 3.7

Uji Simultas (F)

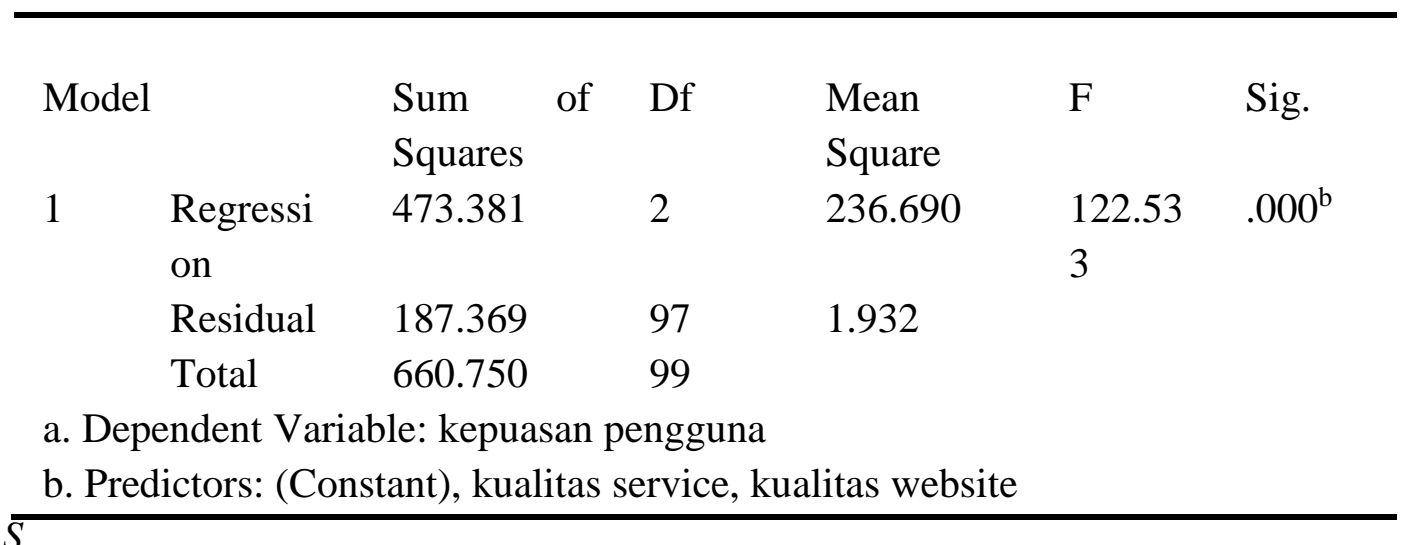

umber data primer: diolah pada tahun 2021

Pada hasil uji simultas (F) yang disajikan pada table diatas menunjukkan nilai signifikansi 0,00 yang artinya kurang dari nilai $\alpha 0,05$, dan nilai $\mathrm{F}$ pada table diatas 
menunjukkan angka 122,533, angka tersebut lebih besar dari nilai $\mathrm{F}$ table yang ditentukan sebelumnya, yaitu 3,09. Dengan jumlah 2 variabel bebas dan 100 responden. Yang menghasilkan nilai $\mathrm{F}$ table sebesar 3,09< 122,533 maka dapat dinyatakan bahwa, kedua variabel (X), kualitas website dan kualitas service pada uji $\mathrm{f}$ yang dilakukan Bersama-sama berpengaruh terhadap variabel (Y) kepuasan pengguna

Table 4.20

Uji Simultas (F)

Variabel Dependent Loyalitas

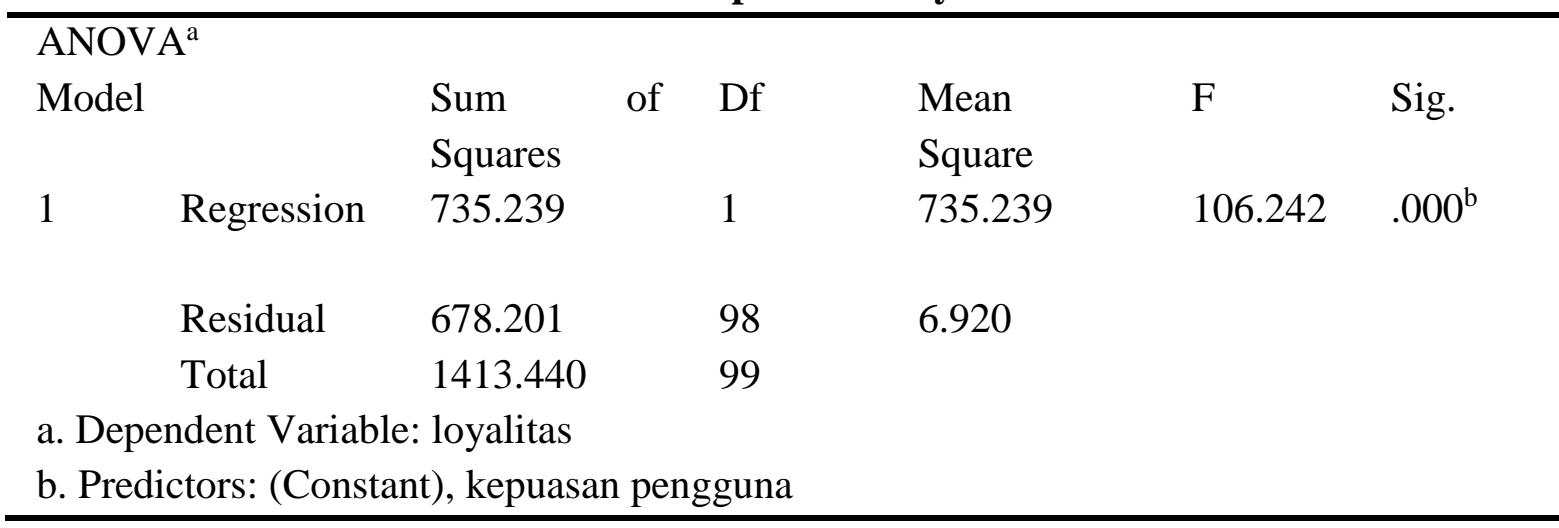

Sumber data premier: diolah pada tahun 2021

Pada hasil $\mathrm{F}$ yang disajikan pada table diatas menunjukkan nilai signifikansi 0,00 yang artinya kurang dari nilai $\alpha 0,05$, dan nilai $\mathrm{F}$ pada table diatas menunjukkan angka 106,242, angka tersebut lebih besar dari nilai F table yang ditentukan sebelumnya, yaitu 3,09. Dengan jumlah 2 variabel bebas dan 100 responden. Yang menghasilkan nilai $F$ table sebesar 3,09<122,533 maka dapat dinyatakan bahwa, variabel $(\mathrm{X})$ yaitu variabel kepuasan pengguna, pada uji $\mathrm{f}$ yang dilakukan Bersama-sama berpengaruh terhadap variabel (Y) Loyalitas

\subsection{Pembahasan}

Berdasarkan hasil pengujian dari hipotesis diatas, dapat dinyatakan bahwa variabel kualitas website berpengaruh positif terhadap kepuasan pengguna, pernyataan ini dibuktikan dari hasil analisis linier berganda yang menunjukkan bahwa nilai sing adalah 0,53 yang artinya bahwa $\mathrm{H}_{1}$ diterima. variabel kualitas service berpengaruh positif terhadap kepuasan pengguna. Hal tersebut diperkuat dengan hasil perhitungan dengan sign 0,000. Dengan ini $\mathrm{H}_{2}$ di terima. kualitas service shopee sudah terlaksana dengan baik, hal ini menggambarkan bahwa indicator kualitas service dari shopee sudah terlaksana. kepercayaan pengguna berpengaruh positif terhadap loyalitas. Hal tersebut diperkuat dengan perhitungan data sign 0,000. Dengan ini dapat disimpulkan bahwa $\mathrm{H}_{3}$ deterima.

\section{KESIMPULAN}

Berdasarkan dari hasil perhitungan data serta pembahasan pada bab sebelumnya, maka dalam penelitian ini menarik kesimpulan bahwa

1) Disimpulkan bahwa kualitas website pada penelitian ini memiliki pengaruh yang positif terhadap kepuasan pengguna shopee, yang artinya website Shopee sudah layak, menarik 
minat beli pengguna Shopee, dan termasuk indicator yang terdapat didalamnya dirasa sudah sesuai. Diantara lain yaitu website shopee sangat informatif dan juga kemudahan penggunaan website, dan kepraktisan dalam berbelanja

2) Disimpulkan bahwa kualitas service memiliki pengaruh yang positif dalam penelitian ini, artinya Shopee memiliki kualitas service yang layak, dengan kualitas service yang layak sehingga pengguna Shopee menjadi nyaman dalam berbelanja.

3) Dapat disimpulkan kepuasan pengguna berpengaruh positif terhadap loyalitas, hal ini dapat juga dikatakan bahwa seorang pengguna Shopee merasa puas berbelanja di Shopee, kepuasan pengguna Shopee dapat juga terjadi karena dalam Shopee banyak penawaranpenawaran yang mengiyurkan sehingga pengguna Shopee akan membeli setelah mereka membeli dan sesuai dengan ekpektasi mereka, maka mereka akan melakukan pembelian ulang.

\section{Saran}

Adapun masukan saya sebagai penulis penelitian ini kepada pihak perusahaan Shopee, dilihat dari tanggapan positif dari pengguna Shopee untuk mempertahankan serta meningkatkan loyalitas pelanggan Shopee dikemudian hari dengan cara meningkatkan kualitas service karena service yang berkualitas sangatlah berpengaruh pada loyalitas pelanggan, jika service yang berkualitas maka akan banyak pelanggan yang akan melakukan pembelian ulang. Mungkin dengan cara melakukan seleksi pada barang dan juga dan menyediakan call center 24 jam. Untuk penelitian selanjutnya saya berharap kepada teman yang akan melakukan penelitian selanjutnya untuk melakukan penelitian perlu mempertimbangkan lokasi, objek serta populasi penelitian yang lebih luas dari penelitian ini atau penelitian yang sebelumnya. Sehingga dapat memberikan dukungan dan sebagai bahan perbandingan tingkat akurasi pada penelitian-penelitian dengan variabel serta model terkait. Untuk penelitian yang selanjutnya menggunakan variabel yang lebih akurat seperti, kepercayaan, komitmen, keamanan.

\section{DAFTAR PUSTAKA}

Hapsari, K., \& Priyadi, Y. (2017). Perancangan Model Data Flow Diagram Untuk Mengukur Kualitas Website Menggunakan Webqual 4.0. Jurnal Sistem Informasi Bisnis, 7(1), 66. https://doi.org/10.21456/vol7iss1pp66-72

Indriyani, F., \& Helling, L. S. (2018). Analisis Pengaruh Kualitas Website , Kepercayaan, Promosi Dan Harga Terhadap Kepuasan Pelanggan Tokopedia. Jurnal Riset Manajemen Sekolah Tinggi Ilmu Ekonomi Widya Wiwaha Program Magister Manajemen, 5(1), 56-68. https://doi.org/10.32477/jrm.v5i1.285

Insana, D. R. M., \& Johan, R. S. (2020). Peningkatan Kepuasan Konsumen Melalui Penggunaan E-Commerce. Sosio e-kons, 12(2), 125-137.

Katadata.co.id. (2019). Indonesia Jadi Negara dengan Pertumbuhan E-Commerce Tercepat di Dunia. Katadata.Co.Id, 2018.

Lubis, A. S., \& Andayani, N. R. (2018). Pengaruh Kualitas Pelayanan (Service Quality) 
Terhadap Kepuasan Pelanggan Pt. Sucofindo Batam. Journal of Applied Business Administration, 1(2), 232-243. https://doi.org/10.30871/jaba.v1i2.619

Puspitasari, A., Kumadji, S., \& Sunarti. (2010). Pengaruh Kualitas Website terhadap Nilai yang dipresepsikan Kepuasan dan Loyalitas Pelanggan pada Online Shop. Jurnal Administrasi Bisnis, 1-9.

Susanto, A., Lee, H., Zo, H., \& P, A. (2013). Factors_affecting_Internet_ban.PDF.pdf.

Udayana, I. B. N., \& Mujino. (2018). MEMBANGUN KEPUASAN PELANGGAN SEBAGAI UPAYA MENINGKATKAN LOYALITAS PADA USAHA KECIL DAN MENENGAH DI DAERAH ISTIMEWA YOGYAKARTA. 1(2), 38-50.

Wiyono, gendro. (2011). Merancang Penelitian Bisnis dengan Alat Analisis SPSS \& SmartPLS. STIM YKPN.

Yulianti, E., \& Umbara, T. (2020). Pelayanan Dengan Metode Importance Performance. 8(2), 78-86. https://doi.org/10.21063/jtif.2020.v8.2.78-86 